\title{
Prognostic role of IDH mutations in gliomas: a meta-analysis of 55 observational studies
}

\author{
Liang $\mathrm{Xia}^{1, *}$, Bin $\mathrm{Wu}^{1,}{ }^{1}$, Zhiquan Fu${ }^{2}$, Fang Feng ${ }^{1}$, Enqi Qiao ${ }^{1}$, Qinglin $\mathrm{Li}^{1}$, Caixing Sun ${ }^{1}$, \\ Minghua $\mathbf{G e}^{1}$ \\ 1 Zhejiang Cancer Hospital, Hangzhou, Zhejiang Province, China \\ ${ }^{2}$ Shanghai Hospital of Integrated Traditional and Western Medicine, Hongkou District, Shanghai, China \\ *These authors have contributed equally to this work
}

Correspondence to:

Qinglin Li, e-mail: f38865319@dlmu.edu.cn

Caixing Sun, e-mail: 2226124552@qq.com

Minghua Ge, e-mail: gemingh@163.com

Keywords: IDH mutations, prognosis, glioma

Received: December 16, $2014 \quad$ Accepted: July 06, $2015 \quad$ Published: July 16, 2015

\section{ABSTRACT}

Background: IDH (Isocitrate dehydrogenase) mutations occur frequently in gliomas, but their prognostic impact has not been fully assessed. We performed a meta-analysis of the association between IDH mutations and survival in gliomas.

Methods: Pubmed and EMBASE databases were searched for studies reporting IDH mutations (IHD1/2 and IDH1) and survival in gliomas. The primary outcome was overall survival (OS); the secondary outcome was progression-free survival (PFS). Hazard ratios (HR) with $95 \%$ confidence interval (CI) were determined using the Mantel-Haenszel random-effect modeling. Funnel plot and Egger's test were conducted to examine the risk of publication bias.

Results: Fifty-five studies (9487 patients) were included in the analysis. Fifty-four and twenty-seven studies investigated the association between IDH1/2 mutations and OS/PFS respectively in patients with glioma. The results showed that patients possessing an IDH1/ 2 mutation had significant advantages in OS ( $\mathrm{HR}=0.39,95 \% \mathrm{CI}$ : $0.34-0.45 ; P<0.001)$ and PFS (HR = 0.42, 95\% CI: 0.35-0.51; $P<0.001)$. Subgroup analysis showed a consistent result with pooled analysis, and patients with glioma of WHO grade III or II-III had better outcomes.

Conclusions: These findings provide further indication that patients with glioma harboring IDH mutations have improved OS and PFS, especially for patients with WHO grade III and grade II-III.

\section{INTRODUCTION}

Gliomas account for more than $50 \%$ of all central nervous system (CNS) tumors [1]. Glioblastomas remain among the deadliest human tumors in spite of recent advances in both diagnostic modalities and therapeutic strategies. Indeed, the 5-year survival rate in patients with glioblastoma is among the lowest for all neoplasms. Indeed, in patients with glioblastoma multiforme, the median survival is 9-12 months [2]. All gliomas are classified from grade I to grade IV according to the 2007 WHO Classification of Cancers of the CNS [3]. Established clinicopathological prognostic factors such as WHO grade, age at diagnosis, performance status, cognitive function, histologic characteristics, and extent of surgical resection had been shown to inadequately predict the clinical outcomes of gliomas [4]. A number of molecular markers with important roles in the formation and progression of gliomas have been identified recently. However, only a few have practical value in the clinical setting [5]. Therefore, identification of novel prognostic markers has a substantial clinical impact on the future management of gliomas.

Isocitrate dehydrogenase $1 / 2$ (IDH1/2) catalyze the oxidative carboxylation of isocitrate to $\alpha$-ketoglutarate, resulting in the reduction of nicotinamide adenine dinucleotide phosphate (NADP) to NADPH, which is necessary for the regeneration of reduced glutathione, which is the main antioxidant in cells [6]. Parsons (2008) 
firstly proposed the presence of mutations in the active site of IDH1/2 in most low-grade gliomas and secondary highgrade gliomas [7]. Several subsequent researches further supported his conclusions and have found that IDH1/2 might be a prognostic factor since patients with a glioma harboring an IDH mutation show significantly better survival than those with a wild-type IDH glioma [8-12]. The latest study with a large sample (1305 patients) and the preceding meta-analysis including 12 studies (2,190 patients) published in 2013 also supports this association $[13,14]$. However, potential heterogeneity was indicated among these studies, which did not explore the prognostic value of IDH mutations based on different clinical and pathological features.

Therefore, the aim of the present study was to synthesize comprehensively the available evidence on the effects of IDH mutations on survival in patients with gliomas.

\section{RESULTS}

\section{Study selection procedure}

The study selection procedure is presented in Figure 1. In the initial literature search, 1283 studies were relevant to the search terms. Of which, we excluded 294 studies because of overlapping data sets. Then, 877 studies were ruled out because of apparent irrelevance when reading the title and/or abstract. An additional 13 relevant studies were included from reference lists. By reading through the full texts of the remaining studies, 62 studies were excluded (22 studies shared an identical population, 23 studies had no relevant outcomes, nine studies were with small sample size, and eight articles were letters, comments or correspondence). Moreover, 8 studies were ruled out due to the duplicate patients. Finally, 55 articles were left with sufficient data for extraction.

\section{Study characteristics}

Characteristics of included studies are summarized in Supplementary Table 1. Fifty-five studies were included: 9 studies from America, 17 from Asia and 29 from Europe [8-11, 13, 17-66]. A total of 9487 patients were included, and the range of mean age was 36 to 64.3 years, and the sample size was 40 to 1305 patients. Twelve studies evaluated grade II gliomas, six examined grade III gliomas, 12 examined grade IV glioma, four evaluated grades I-IV tumors, three evaluated grades II-III tumors, five examined grades III-IV gliomas and 13 evaluated grades II-IV gliomas.

\section{IDH 1 and IDH1/2 mutations and OS in gliomas}

Fifty-four of 55 studies investigated the association between IDH1/2 mutations and OS of patients with glioma. The combined analysis showed that upon comparing patients without IDH1/2 mutations, patients possessing a mutation had a significant OS advantage $(\mathrm{HR}=0.39$,
95\%CI: $0.34-0.45 ; P<0.001$ ) (Table 1, Figure 2). Since statistically significant heterogeneity was observed between the studies ( $12=54.8, P<0.001)$, further subgroup analyses were conducted according to the IDH1/2 and IDH1 mutations, study origin, sample size, follow up period, patient age, mutation detection method, survival analysis and WHO grade. Regarding the publication bias in the studies, we found no funnel plot asymmetry. Furthermore, the results of the Egger's test did not show any evidence of publication bias $(P=0.230$ for OS, Figure 4A).

\section{IDH1/2 mutations and PFS in gliomas}

Twenty-seven studies provided data concerning the association between IDH1/2 mutations and PFS of glioma patients. The combined analysis of the included studies showed that upon comparing patients without IDH1/2 mutations, patients possessing a mutations status had a significant PFS advantage $(\mathrm{HR}=0.42,95 \% \mathrm{CI}$ : $0.35-0.51 ; P<0.001$ ) (Table 1, Figure 3). Statistically significant heterogeneity was observed between the studies $(\mathrm{I} 2=59.2)$. No funnel plot asymmetry was found, and the Egger's test did not show any evidence of publication bias $(P=0.783$ for PFS; Figure 4B).

\section{Subgroup analysis}

Table 1 presents the subgroup analyses of the relationship between IDH mutations and OS and PFS. There was no difference in OS and PFS between patients with IDH1 and IDH1/2 mutations $(P=0.17$ and $P=$ 0.55 , respectively). Therefore, these two groups of patients were analyzed together in the next subgroup analyses. Country of origin had no impact on OS $(P=0.28)$, but was associated with a better PFS in North America $(\mathrm{HR}=0.15,95 \% \mathrm{CI}: 0.05-0.42)$ compared with Asia (HR $=0.44,95 \% \mathrm{CI}$ : 0.32-0.60) and Europe $(\mathrm{HR}=0.54,95 \% \mathrm{CI}: 0.45-0.64)(P=0.03)$. Sample size of the study, follow-up period, age, and mutation detection method had no effect on OS and PFS. Multivariate survival analysis led to a better OS $(P=$ 0.04 ) compared with other methods, but had no effect on PFS. Finally, WHO grade had an impact on both OS $(P$ $=0.0003)$ and PFS $(P=0.006)$. Supplementary Table S2 presents the OS and PFS for each individual study.

\section{DISCUSSION}

\section{Principal findings}

The present meta-analysis showed that patients with gliomaharboring IDH1/2 (including IDH1 mutation) had a significant OS and PFS advantage over those without IDH1/2 mutations. Specifically, harboring a mutation in IDH1/2 mutation reduced overall mortality by $61 \%$ and progression-free mortality by $58 \%$ compared with the 


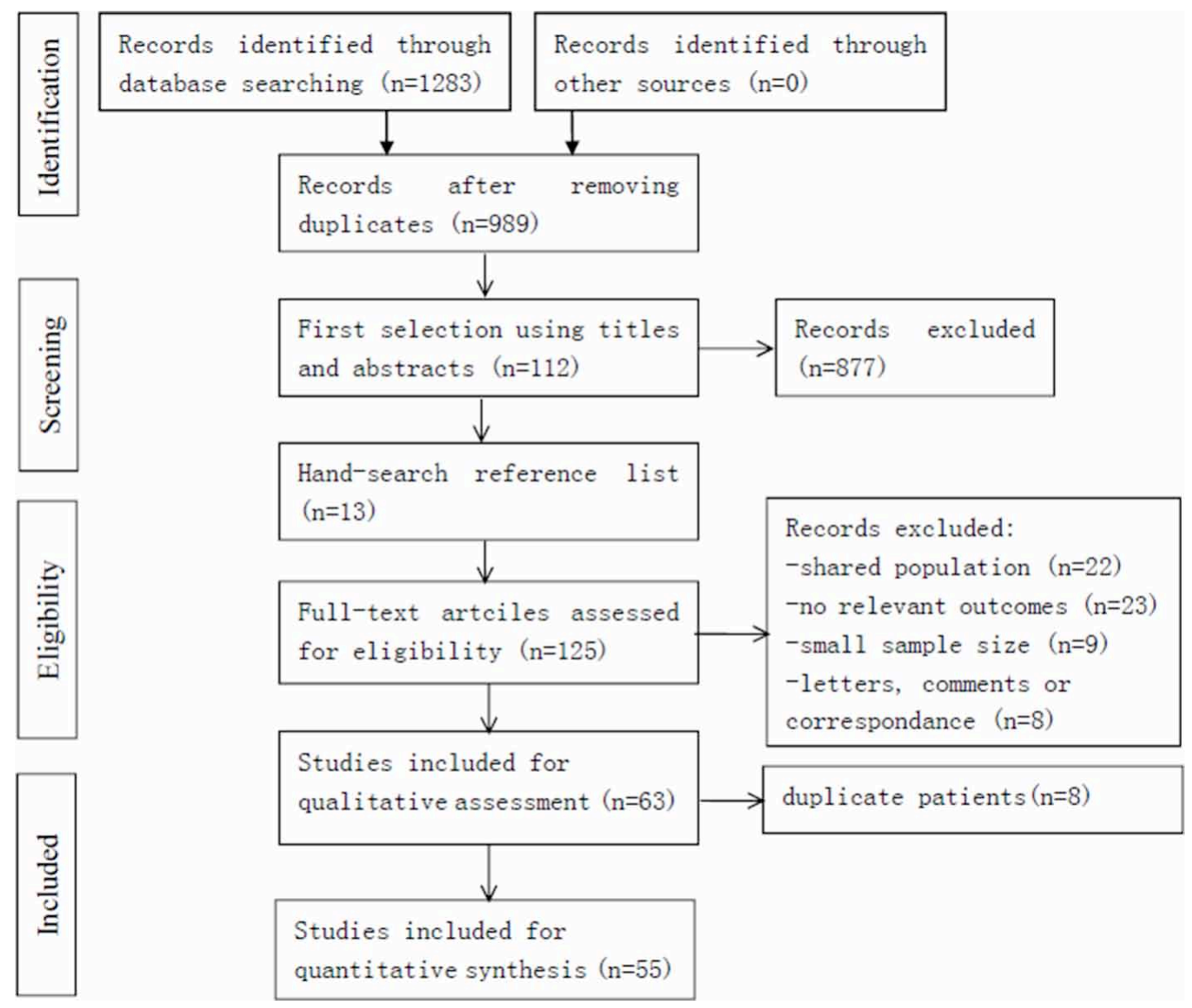

Figure 1: Flowchart of the included studies.

wild-type genes. At the same time, the summary HRs across studies calculated for each subgroup did not alter substantially the OS and PFS results for IDH1/2, despiting subgroup "Others" of "survival analysis" in OS and "IV" of "WHO grades" in PFS. Finally, results suggest that the methodology used to assess IDH mutation is not very important. Indeed, sequencing is more sensitive than immunochemistry but given that more than $90 \%$ of IDH mutations are IDH1 mutations and that in these mutations the $\mathrm{R} 132 \mathrm{H}$ one is found in more than $90 \%$ of cases, immunochemistry is a reliable diagnosis technique due to its high sensitivity and specificity $[32,67]$.

\section{Potential tumorigenesis mechanism and prognostic value of IDH in glioma}

IDH1 and IDH2 genes have become a focus for research aimed at understanding the biology of gliomas [6]. Mutations in these genetic loci, first discovered in 2008, occur in a large proportion of low-grade gliomas and secondary glioblastomas [7]. Researchers have found that IDH mutationsare relatively glioma-specific and are likely to be a direct cancer driver in the early stage of gliomagenesis [6]. Firstly, IDH mutations produce 2-hydroxyglutarate (2-HG) and it functions as a possible oncometabolitecontributing to the tumorigenesis and progression of gliomas [68]. Studies have shown that 2 -HG is equivalent to $\alpha$-ketoglutarate in structure, and competitively suppresses the activity of dioxygenases [69]. Thus, suppression of dioxygenases by 2-HG is believed to be one of the mechanisms through which IDH mutations lead to the pathogenesis of gliomas. Secondly, IDH1 mutant can inhibit the activity of the prolyl hydroxylase and hence the stability of the hypoxia-inducible factor $1 \alpha$ (HIF $1 \alpha)$ by reduced production of $\alpha$-ketoglutarate and increased production of 2-HG [70]. Finally, HIF1 $\alpha$ can activate a series of target genes that might promote glioma cell growth, invasion, angiogenesis, and metastasis [71]. Thirdly, IDH1 mutation may be closely linked to the epigenetic program [72]. The Cpg Island Methylator Phenotype (CIMP) is a powerful determinant of glioma pathogenicity. Turcan et al [72] study has shown that IDH1 mutation contributes to the establishment of glioma-CIMP by rebuilding the methylome. Their findings indicated that IDH mutations might be a molecular basis of CIMP in gliomas, providing a direction for understanding oncogenesis in human glioma. 
Table 1: Subgroup analyses of the relationships between IDH mutations and overall survival or progression-free-survival

\begin{tabular}{|c|c|c|c|c|c|c|}
\hline \multirow[t]{3}{*}{ Comparison variables } & \multicolumn{3}{|l|}{ Overall survival } & \multicolumn{3}{|c|}{ Progression-free survival } \\
\hline & Number & & Interaction & Number & & Interaction \\
\hline & $\begin{array}{l}\text { Heterogeneity } \\
\left(\mathrm{I}^{2} \text { statistics; }\right. \\
\%)\end{array}$ & $\begin{array}{c}\text { HR 95\%CI, } \\
P \text { value }\end{array}$ & $P$ value & $\begin{array}{c}\text { Heterogeneity } \\
\text { (I² statistics; } \\
\%)\end{array}$ & $\begin{array}{c}\text { HR 95\%CI, } \\
P \text { value }\end{array}$ & $P$ value \\
\hline Total & $54(54.7)$ & $\begin{array}{c}0.39(0.34 \text { to } \\
0.45),<0.001\end{array}$ & NA & $27(59.15)$ & $\begin{array}{c}0.42(0.35 \text { to } \\
0.51),<0.001\end{array}$ & NA \\
\hline Mutation & & & 0.17 & & & 0.55 \\
\hline IDH1 & $34(58.7)$ & $\begin{array}{c}0.42(0.35 \text { to } \\
0.50),<0.001\end{array}$ & & $16(71.8)$ & $\begin{array}{c}0.50(0.36 \text { to } \\
0.68),<0.001\end{array}$ & \\
\hline IDH1/2 & $20(58.3)$ & $\begin{array}{c}0.37(0.30 \text { to } \\
0.47),<0.001\end{array}$ & & $11(78.4)$ & $\begin{array}{c}0.42(0.33 \text { to } \\
0.53),<0.001\end{array}$ & \\
\hline \multicolumn{7}{|l|}{ Origin country } \\
\hline North America & $9(45.2)$ & $\begin{array}{c}0.30(0.22 \text { to } \\
0.43),<0.001\end{array}$ & 0.28 & 1 (NA) & $\begin{array}{c}0.15(0.05 \text { to } \\
0.42),<0.001\end{array}$ & 0.03 \\
\hline Asian & $16(52.6)$ & $\begin{array}{c}0.40(0.32 \text { to } \\
0.50),<0.001\end{array}$ & & $12(74.2)$ & $\begin{array}{c}0.44(0.32 \text { to } \\
0.60),<0.001\end{array}$ & \\
\hline Europe & $29(56.3)$ & $\begin{array}{c}0.42(0.36 \text { to } \\
0.48),<0.001\end{array}$ & & $14(62.1)$ & $\begin{array}{c}0.54(0.45 \text { to } \\
0.64),<0.001\end{array}$ & \\
\hline \multicolumn{7}{|l|}{ Sample size } \\
\hline$\geq 200$ & $16(52.9)$ & $\begin{array}{c}0.41(0.36 \text { to } \\
0.48),<0.001\end{array}$ & 0.34 & $8(67.6)$ & $\begin{array}{c}0.46(0.38 \text { to } \\
0.55),<0.001\end{array}$ & 075 \\
\hline$<200$ & $38(54.8)$ & $\begin{array}{c}0.37(0.31 \text { to } \\
0.45),<0.001\end{array}$ & & $19(77.2)$ & $\begin{array}{c}0.49(0.34 \text { to } \\
0.69),<0.001\end{array}$ & \\
\hline \multicolumn{7}{|l|}{ Follow up period } \\
\hline Referred & $20(58.3)$ & $\begin{array}{c}0.37(0.30 \text { to } \\
0.47),<0.001\end{array}$ & 0.64 & $13(81.3)$ & $\begin{array}{c}0.45(0.30 \text { to } \\
0.66),<0.001\end{array}$ & 0.77 \\
\hline No Referred & $34(51.0)$ & $\begin{array}{c}0.40(0.35 \text { to } \\
0.46),<0.001\end{array}$ & & $14(60)$ & $\begin{array}{c}0.50(0.42 \text { to } \\
0.59),<0.001\end{array}$ & \\
\hline \multicolumn{7}{|l|}{ Median/mean age $y$} \\
\hline$>45$ & $18(52.2)$ & $\begin{array}{c}0.38(0.31 \text { to } \\
0.46),<0.001\end{array}$ & 0.15 & $8(78.2)$ & $\begin{array}{c}0.41(0.30 \text { to } \\
0.55),<0.001\end{array}$ & 0.10 \\
\hline$<45$ & $19(56.7)$ & $\begin{array}{c}0.46(0.38 \\
\text { to. } 0.57),< \\
0.001\end{array}$ & & $13(77.8)$ & $\begin{array}{c}0.58(0.43 \text { to } \\
0.80), 0.001\end{array}$ & \\
\hline NR & $17(43.4)$ & $\begin{array}{c}0.34(0.28 \text { to } \\
0.42),<0.001\end{array}$ & & $8(30.0)$ & $\begin{array}{c}0.38(0.30 \text { to } \\
0.49),<0.001\end{array}$ & \\
\hline \multicolumn{7}{|l|}{ Mutation detection } \\
\hline Direct sequencing & $31(52.9)$ & $\begin{array}{c}0.42(0.36 \text { to } \\
0.48),<0.001\end{array}$ & 0.07 & $15(77.4)$ & $\begin{array}{c}0.50(0.41 \text { to } \\
0.62),<0.001\end{array}$ & 0.35 \\
\hline Pyro-sequencing & $9(52.9)$ & $\begin{array}{c}0.42(0.29 \text { to } \\
0.59),<0.001\end{array}$ & & $5(63.3)$ & $\begin{array}{c}0.49(0.30 \text { to } \\
0.80), 0.005\end{array}$ & \\
\hline
\end{tabular}

(Continued) 


\begin{tabular}{|c|c|c|c|c|c|c|}
\hline \multirow[t]{3}{*}{ Comparison variables } & \multicolumn{3}{|l|}{ Overall survival } & \multicolumn{3}{|c|}{ Progression-free survival } \\
\hline & $\begin{array}{c}\text { Number } \\
\text { of studies, } \\
\text { Heterogeneity }\end{array}$ & & Interaction & $\begin{array}{c}\text { Number } \\
\text { of studies, } \\
\text { Heterogeneity }\end{array}$ & & Interaction \\
\hline & $\begin{array}{c}\left(I^{2} \text { statistics; }\right. \\
\%)\end{array}$ & $\begin{array}{c}\text { HR 95\%CI, } \\
P \text { value }\end{array}$ & $P$ value & $\begin{array}{c}\text { (I } \mathbf{I}^{2} \text { statistics; } \\
\% \text { ) }\end{array}$ & $\begin{array}{l}\text { HR } 95 \% \text { CI, } \\
P \text { value }\end{array}$ & $P$ value \\
\hline Immunohistochemistry & $12(53.9)$ & $\begin{array}{c}0.35 \text { ( } 0.25 \text { to } \\
0.49),<0.001\end{array}$ & & $6(66.3)$ & \begin{tabular}{|c|}
$0.33(0.18$ to \\
$0.60),<0.001$
\end{tabular} & \\
\hline NR & $2(21.1)$ & $\begin{array}{c}0.23(0.15 \text { to } \\
0.36),<0.001\end{array}$ & & $1(0.0)$ & \begin{tabular}{|c|}
$0.36(0.24$ to \\
$0.54),<0.001$ \\
\end{tabular} & \\
\hline \multicolumn{7}{|l|}{ Survival analysis } \\
\hline Multivariate & $43(52.6)$ & $\begin{array}{c}0.37(0.32 \text { to } \\
0.42),<0.001\end{array}$ & 0.04 & $24(70.9)$ & $\begin{array}{c}0.44(0.37 \text { to } \\
0.52),<0.001\end{array}$ & 0.10 \\
\hline Others & $11(42.6)$ & $\begin{array}{c}0.48(0.39 \text { to } \\
0.58),<0.001\end{array}$ & & $3(86.6)$ & $\begin{array}{l}1.07(0.37 \text { to } \\
3.07), 0.902\end{array}$ & \\
\hline \multicolumn{7}{|l|}{ WHO grade } \\
\hline II & $17(59.5)$ & $\begin{array}{c}0.45(0.35 \text { to } \\
0.59),<0.001\end{array}$ & 0.0003 & $13(60.4)$ & $\begin{array}{l}0.66(0.48 \text { to } \\
0.90), 0.009\end{array}$ & 0.006 \\
\hline III & $11(10.1)$ & $\begin{array}{c}0.27(0.22 \text { to } \\
0.32),<0.001\end{array}$ & & $7(85.1)$ & \begin{tabular}{|c|}
$0.22(0.12$ to \\
$0.42),<0.001$ \\
\end{tabular} & \\
\hline IV & $20(46.1)$ & $\begin{array}{c}0.49(0.40 \text { to } \\
0.60),<0.001\end{array}$ & & $9(75.2)$ & $\begin{array}{l}0.65(0.41 \text { to } \\
1.05), 0.078 \\
\end{array}$ & \\
\hline II-III & $4(62.4)$ & $\begin{array}{c}0.28(0.14 \text { to } \\
0.54),<0.001\end{array}$ & & $3(25.0)$ & $\begin{array}{c}0.32(0.21 \text { to } \\
0.48),<0.001\end{array}$ & \\
\hline III-IV & $5(58.6)$ & $\begin{array}{c}0.40(0.28 \text { to } \\
0.57),<0.001\end{array}$ & & $2(36.1)$ & $\begin{array}{c}0.40(0.25 \text { to } \\
0.66),<0.001\end{array}$ & \\
\hline II-IV & $8(0.0)$ & $\begin{array}{c}0.39(0.32 \text { to } \\
0.49),<0.001\end{array}$ & & $5(8.0)$ & $\begin{array}{c}0.41(0.34 \text { to } \\
0.49),<0.001\end{array}$ & \\
\hline
\end{tabular}

IDH mutations may serve as prognostic factors and are strongly correlated with good prognosis in patients with glioma. Many studies have shown that the median OS of patients whose glioblastoma harbor an IDH1 and IDH2 mutations was significantly longer than that of patients whose glioblastoma harbor wild-type IDH [30, $54,73]$. In addition, IDH mutations are associated with better prognosis in patients with anaplastic astrocytoma [57]. Subsequent multivariate analysis confirmed that IDH1 mutation may be an independent favorable prognostic marker in glioblastoma and anaplastic glioma after adjustment for other genomic profiles and treatment modalities [74]. The present meta-analysis further confirms the prognostic value of IDH mutations based on different clinical and pathological featuresreported in 55 observational studies (9487 patients).

\section{Comparison with other studies}

The results from this meta-analysis are broadly consistent with two previously published studies, a meta- analysis of nine studies in glioblastoma [75] and a metaanalysis of twelve studies [14] in adults with different grades of gliomas. These two studies found that IDH1/2 mutations significantly improved the outcomes for patients with glioma. However, in contrast to the two previous meta-analyses, the present meta-analysis included 55 independent publications, with 9487 glioma cases, which should meaningfully increase the statistical power and accurately estimate the effect of IDH1/2 mutations on the prognosis of patients with glioma. In addition, we also conducted more detailed subgroup analyses based on more different clinical and pathological features to systematically evaluate the prognostic effect of IDH mutation and identify potential sources of heterogeneity. Especially, subgroup analyses according to WHO grade revealed that the presence of IDH mutations was associated with a better outcome in patients with WHO grade III and grade II-III. Furthermore, in the present meta-analysis, most of the HRs from the included studies were from multivariate analyses adjusting for confounding factors. Indeed, the adjusted HRs are more 


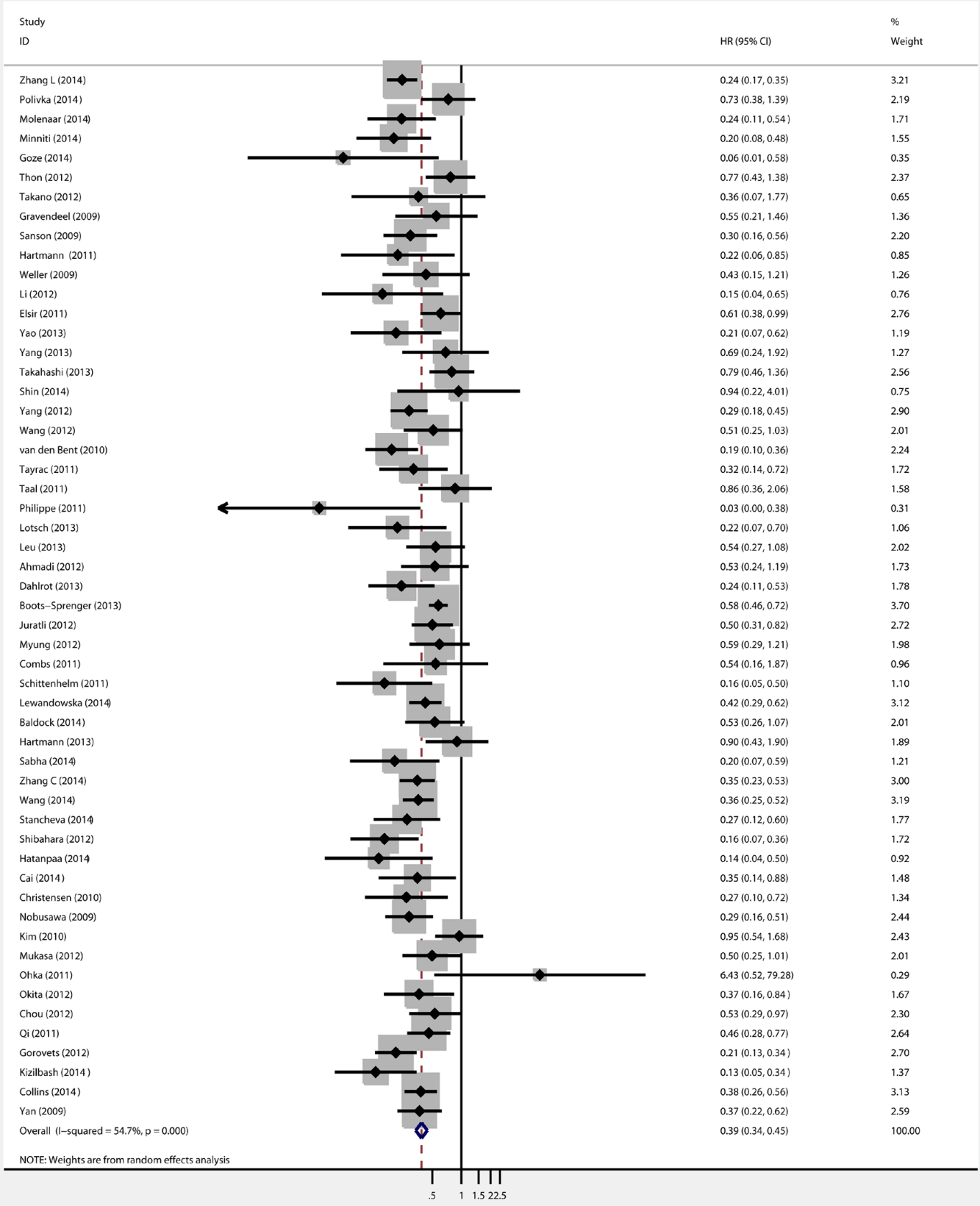

Figure 2: Forest plot of $\mathrm{HR}$ and 95\%CI of the association between IDH1/2 mutations and OS of gliomas.

accurate than the unadjusted HRs since they reduce the risk of bias from other possible confounding factors. Hence, the findings from the present meta-analysis provide strong evidence that IDH mutations carry a very strong prognostic significance for PFS and OS in patients with glioma. Finally, a significant insight from this research is that our included study population was mainly from three continents including eighteen countries. Therefore, the present study ensures an extensive value for the use of IDH mutations in the prognosis of patients with glioma.

\section{Limitations}

The present meta-analysis may have several limitations that need to be addressed. First, in spite of the comprehensive search strategy, we cannot avoid the possibility of having missed relevant studies, in particular studies published in languages other than English. There may have been negative studies that were never published as full-length articles, and the original data of several studies could not be obtained. Secondly, we based our analyses on retrospective studies 
Study

ID

Zhang L (2014)

Polivka (2014)

Minniti (2014)

Goze (2014)

Thon (2012)

Takano (2012)

Hartmann (2011)

Weller (2009)

Yao (2013)

Shin (2014)

Yang (2012)

Wang (2012)

Taal (2011)

Ahmadi (2012)

Dahlrot (2013)

Myung (2012)

Sabha (2014)

Zhang C (2014)

Wang (2014)

Shibahara (2012)

Metellus (2010)

Mukasa (2012)

Okita (2012)

Qi (2011)

Sanson (2009)

Ohka (2011)

Juratli (2012)

Overall $(I-$ squared $=56.0 \%, p=0.000)$

NOTE: Weights are from random effects analysis
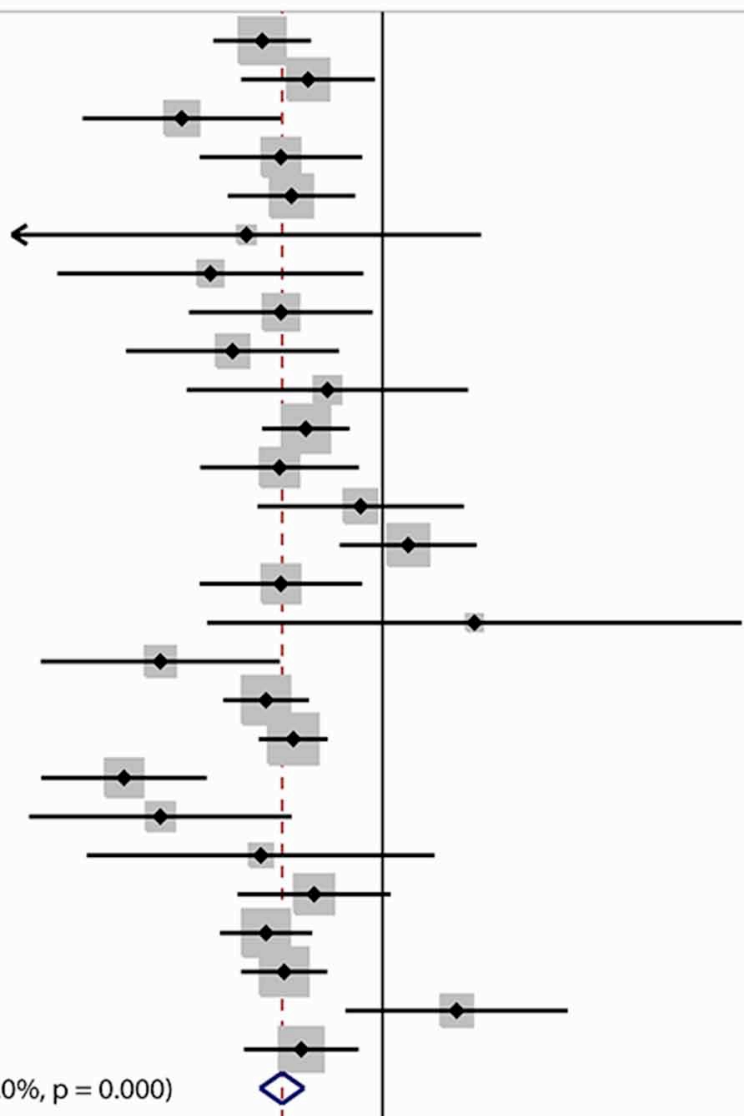

.5
$\%$

$\mathrm{HR}(95 \% \mathrm{Cl}) \quad$ Weight

$0.36(0.24,0.54) \quad 5.71$

$0.53(0.30,0.94) \quad 4.57$

$0.18(0.08,0.42) \quad 3.04$

$0.42(0.21,0.84) \quad 3.81$

$0.46(0.27,0.79) \quad 4.75$

$0.31(0.04,2.32) \quad 0.79$

$0.23(0.06,0.85) \quad 1.63$

$0.42(0.19,0.92) \quad 3.33$

$0.28(0.11,0.69) \quad 2.77$

$0.63(0.19,2.08) \quad 1.86$

$0.52(0.36,0.76) \quad 6.04$

$0.41(0.21,0.82) \quad 3.90$

$0.83(0.34,2.00) \quad 2.88$

$1.25(0.70,2.24) \quad 4.48$

$0.42(0.21,0.84) \quad 3.81$

$2.20(0.22,21.53) \quad 0.62$

$0.15(0.05,0.42) \quad 2.37$

$0.37(0.26,0.53) \quad 6.10$

$0.47(0.35,0.63) \quad 6.64$

$0.11(0.05,0.22) \quad 3.73$

$0.15(0.05,0.46) \quad 2.07$

$0.35(0.08,1.56) \quad 1.33$

$0.56(0.29,1.07) \quad 4.04$

$0.37(0.25,0.55) \quad 5.88$

$0.43(0.30,0.62) \quad 6.08$

$1.89(0.73,4.87) \quad 2.62$

$0.50(0.31,0.82) \quad 5.15$

$0.42(0.35,0.51) \quad 100.00$

Figure 3: Forest plot of HR and 95\%CI of the association between IDH1/2 mutations and PFS of gliomas.
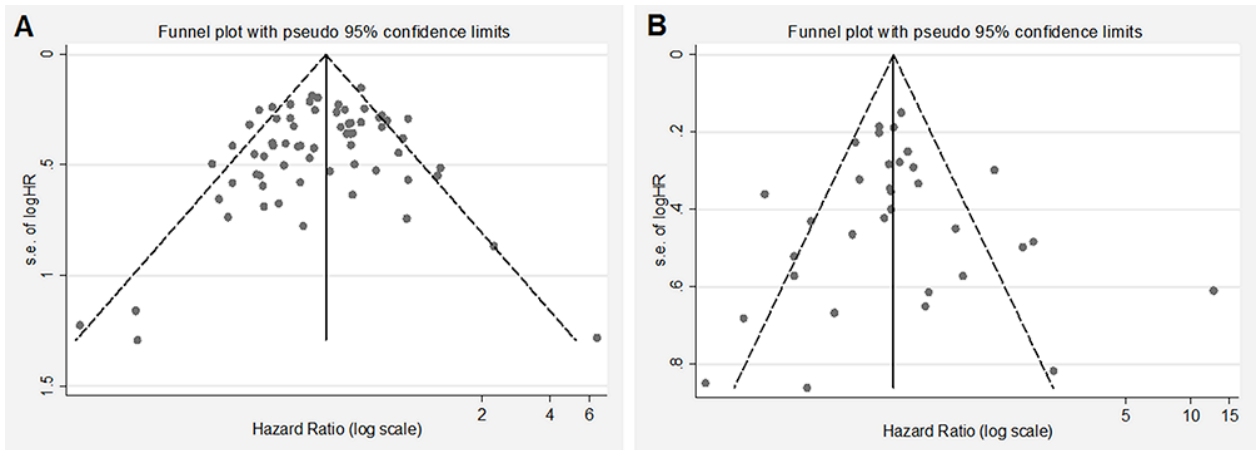

Figure 4: Egger's funnel plot for the publication bias test of the IDH1/2 mutations and OS A. or PFS B. of human gliomas 
rather than prospective studies, so that it is hard to effectively avoid recall and selection biases. Thirdly, several of the HRs in the included studies were from rough estimates of KaplanMeier survival curves, so the results may be not so accurate. Fourthly, most of the HRs were from multivariate analyses by adjusting for confounding factors; however, there were different confounding factors in different included studies. Therefore, the merged HRs have a degree of heterogeneity. Fourthly, the proportion of histological subtypes varies between studies, suggesting a potential diagnostic bias between centers. Finally, evident heterogeneity existed for several outcomes that could not be explained substantially by our present subgroups. This limits our understanding of the association in various settings and restricts the general is ability of our findings.

\section{MATERIALS AND METHODS}

\section{Search strategy and study selection}

A comprehensive search of the English medical literature was conducted on studies evaluating the effect of IDH1/2 mutation on the survival of patients with glioma. Pubmed and EMBASE were searched by using the terms ("Glioma" or "Glioblastoma") and ("Isocitrate Dehydrogenase" or "Isocitrate Dehydrogenase-1" or "IDH1" or "IDH2" or "IDH") and ("Mutation") and ("Survival" or "Mortality" or "Prognosis"). The literature search was executed in November 2014. Detailed search strategies for both databases are shown in Supplementary Appendix 1. Furthermore, we manually searched references in pertinent studies that were identified during the screening processes.

All candidate studies were reviewed by two independent reviewers (Xia L and Li QL). Discrepancies were resolved by discussion. Our search was initially narrowed based on the title followed by the abstract, and finally full papers were reviewed if they were categorized as relevant studies. All of the references from review papers and original reports were examined for further relevant studies. Including criteria for selecting the studies for our analysis were: (i) the diagnosis of glioma was made by pathological examination; (ii) correlation of mutant IDH1/2 with OS or PFS was reported; (iii) the study was the most recent or comprehensive report if the same group or author reported results procured from the same glioma patient population in more than one article; (iv) the papers that were not directly providing hazard ratios (HRs)/odds ratios (ORs) and 95\% confidence intervals (CI) were kept if we could rebuild them using the $P$ values and other data reported; (v) studies had more than 40 patients; and (vi) studies published in English.

\section{Data extraction}

Two reviewers (Xia L and $\mathrm{Li} \mathrm{QL}$ ) independently extracted data from included studies: first author's name, year of publication, country of the population studied, number of patients, patient age, WHO grade, percentage of IDH mutant, IDH mutation type, primary or secondary, mutation detection method, treatment regimen, survival data including OS and PFS, follow-up period, survival analysis, and adjusted variables. OS (overall survival) was defined from the medical treatment until death or last follow-up. PFS (progression free survival) was calculated as the interval between the date of treatment and the detection of the recurrence or death from any cause. Disagreements were addressed by discussion with a third reviewer (Li Qinglin) until the two first reviewers reached a consensus or by contacting experts if necessary.

\section{Quality assessment of primary studies}

Quality assessment of included primary studies was independently performed by two reviewers (Xia L and Li QL) using the Newcastle-Ottawa Quality Assessment Scale (NOS) [15]. NOS scores of $\geq 6$ were defined as high-quality studies. Any disagreement was solved by discussion.

\section{Statistical analysis}

The Stata 12.0 statistical software (Stata Corporation, College Station, TX, USA) was used to perform the metaanalysis. Hazard ratio (HR) and 95\%CI were obtained directly from each article or from an estimation of the Kaplan-Meier survival curves using the methods by Parmar et al [16]. An HR $<1$ indicated a better prognosis in patients with glioma and IDH mutation, whereas an HR $>1$ implied a poor prognosis. If several HR estimates were presented in the same study, we chose the most powerful one (multivariate analysis was superior to univariate analysis, and univariate analysis was superior to unadjusted Kaplan-Meier analysis).

The Cochrane's Q statistic was used to evaluate the heterogeneity of the primary studies. I $>50 \%$ is defined as a measure of severe heterogeneity. The randomeffects model, which is generally more conservative, was chosen. In addition, subgroup analyses were performed to investigate the potential causes of heterogeneity according to IDH1/2 and IDH1 mutations, study origin, sample size, follow-up period, patient age, mutation detection method, survival analysis and WHO grade.

Publication bias was first assessed by visual judgment of a funnel plot, and then performed for each of the pooled study groups using the Egger's test. All $P$ values were twosided and the significance level was set at 0.05 .

\section{CONCLUSION}

In conclusion, this meta-analysis provides more strong evidence that IDH1/2 mutations is an independent prognostic factor for patients with different grades of glioma and that IDH1/2 mutations is associated with improved OS and PFS, especially for patients with WHO grade III and grade II-III. 


\section{ACKNOWLEDGMENTS}

The study was sponsored by the Natural Science Program of Zhe jiang Department of Finance (No.: LY12H16032) and the Youth Scientific Innovation Foundation of Zhejiang Cancer Hospital (No.: QN201402).

\section{CONFLICTS OF INTEREST}

All authors declare that they have no conflict of interests.

\section{REFERENCES}

1. Stupp R, Tonn JC, Brada M, Pentheroudakis G. High-grade malignant glioma: ESMO Clinical Practice Guidelines for diagnosis, treatment and follow-up. Annals of oncology : official journal of the European Society for Medical Oncology / ESMO. 2010; 21:v190-193.

2. Ohgaki H, Kleihues P. Epidemiology and etiology of gliomas. Acta neuropathologica. 2005; 109:93-108.

3. Feiden S, Feiden W. [WHO classification of tumours of the CNS: revised edition of 2007 with critical comments on the typing und grading of common-type diffuse gliomas]. Der Pathologe. 2008; 29:411-421.

4. Fuentes-Raspall R, Vilardell L, Perez-Bueno F, Joly C, Garcia-Gil M, Garcia-Velasco A, et al. Population-based incidence and survival of central nervous system (CNS) malignancies in Girona (Spain) 1994-2005. Journal of neuro-oncology. 2011; 101:117-123.

5. Huse JT, Aldape KD. The evolving role of molecular markers in the diagnosis and management of diffuse glioma. Clinical cancer research : an official journal of the American Association for Cancer Research. 2014; 20:5601-5611.

6. Zhang C, Moore LM, Li X, Yung WK, Zhang W. IDH1/2 mutations target a key hallmark of cancer by deregulating cellular metabolism in glioma. Neuro-oncology. 2013; 15:1114-1126.

7. Parsons DW, Jones S, Zhang X, Lin JC, Leary RJ, Angenendt $\mathrm{P}$, et al. An integrated genomic analysis of human glioblastoma multiforme. Science. 2008; 321:1807-1812.

8. Sanson M, Marie Y, Paris S, Idbaih A, Laffaire J, Ducray F, et al. Isocitrate dehydrogenase 1 codon 132 mutation is an important prognostic biomarker in gliomas. Journal of clinical oncology : official journal of the American Society of Clinical Oncology. 2009; 27:4150-4154.

9. Buccoliero AM, Castiglione F, Degl'Innocenti DR, Gheri CF, Genitori L, Taddei GL. IDH1 mutation in pediatric gliomas: has it a diagnostic and prognostic value?. Fetal and pediatric pathology. 2012; 31:278-282.

10. Weller M, Felsberg J, Hartmann C, Berger H, Steinbach JP, Schramm J, et al. Molecular predictors of progression-free and overall survival in patients with newly diagnosed glioblastoma: a prospective translational study of the German Glioma Network. Journal of clinical oncology : official journal of the American Society of Clinical Oncology. 2009; 27:5743-5750.

11. Molenaar RJ, Verbaan D, Lamba S, Zanon C, Jeuken JW, Boots-Sprenger SH, et al. The combination of IDH1 mutations and MGMT methylation status predicts survival in glioblastoma better than either IDH1 or MGMT alone. Neuro-oncology. 2014; 16:1263-1273.

12. Labussiere M, Boisselier B, Mokhtari K, Di Stefano AL, Rahimian A, Rossetto M, et al. Combined analysis of TERT, EGFR, and IDH status defines distinct prognostic glioblastoma classes. Neurology. 2014; 83:1200-1206.

13. Wang XW, Ciccarino P, Rossetto M, Boisselier B, Marie Y, Desestret $\mathrm{V}$, et al. IDH mutations: genotype-phenotype correlation and prognostic impact. BioMed research international. 2014; 2014:540236.

14. Zou P, Xu H, Chen P, Yan Q, Zhao L, Zhao P, et al. IDH1/ IDH2 mutations define the prognosis and molecular profiles of patients with gliomas: a meta-analysis. PloS one. 2013; 8:e68782.

15. Stang A. Critical evaluation of the Newcastle-Ottawa scale for the assessment of the quality of nonrandomized studies in meta-analyses. European journal of epidemiology. 2010; 25:603-605.

16. Parmar MK, Torri V, Stewart L. Extracting summary statistics to perform meta-analyses of the published literature for survival endpoints. Statistics in medicine. 1998; 17:2815-2834.

17. Hartmann C, Hentschel B, Simon M, Westphal M, Schackert G, Tonn JC, et al. Long-term survival in primary glioblastoma with versus without isocitrate dehydrogenase mutations. Clinical cancer research : an official journal of the American Association for Cancer Research. 2013; 19:5146-5157.

18. Sabha N, Knobbe CB, Maganti M, Al Omar S, Bernstein M, Cairns R, et al. Analysis of IDH mutation, $1 \mathrm{p} / 19 \mathrm{q}$ deletion, and PTEN loss delineates prognosis in clinical low-grade diffuse gliomas. Neuro-oncology. 2014; 16:914-923.

19. Zhang CB, Bao ZS, Wang HJ, Yan W, Liu YW, Li MY, et al. Correlation of IDH1/2 mutation with clinicopathologic factors and prognosis in anaplastic gliomas: a report of 203 patients from China. Journal of cancer research and clinical oncology. 2014; 140:45-51.

20. Zhang L, Wang M, Wang W, Mo J. Incidence and prognostic value of multiple gene promoter methylations in gliomas. Journal of neuro-oncology. 2014; 116:349-356.

21. Stancheva G, Goranova T, Laleva M, Kamenova M, Mitkova A, Velinov N, et al. IDH1/IDH2 but not TP53 mutations predict prognosis in Bulgarian glioblastoma patients. BioMed research international. 2014; 2014:654727.

22. Shibahara I, Sonoda Y, Kanamori M, Saito R, Yamashita Y, Kumabe $\mathrm{T}$, et al. IDH1/2 gene status defines the 
prognosis and molecular profiles in patients with grade III gliomas. International journal of clinical oncology. 2012; 17:551-561.

23. Polivka J, Polivka J Jr, Rohan V, Pesta M, Repik T, Pitule $\mathrm{P}$, et al. Isocitrate dehydrogenase-1 mutations as prognostic biomarker in glioblastoma multiforme patients in West Bohemia. BioMed research international. 2014; 2014:735659.

24. Minniti G, Scaringi C, Arcella A, Lanzetta G, Di Stefano D, Scarpino S, et al. IDH1 mutation and MGMT methylation status predict survival in patients with anaplastic astrocytoma treated with temozolomide-based chemoradiotherapy. Journal of neuro-oncology. 2014; 118:377-383.

25. Hatanpaa KJ, Hu T, Vemireddy V, Foong C, Raisanen JM, Oliver D, et al. High expression of the stem cell marker nestin is an adverse prognostic factor in WHO grade II-III astrocytomas and oligoastrocytomas. Journal of neurooncology. 2014; 117:183-189.

26. Goze C, Blonski M, Le Maistre G, Bauchet L, Dezamis E, Page $\mathrm{P}$, et al. Imaging growth and isocitrate dehydrogenase 1 mutation are independent predictors for diffuse low-grade gliomas. Neuro-oncology. 2014; 16:1100-1109.

27. Cai J, Yang P, Zhang C, Zhang W, Liu Y, Bao Z, et al. ATRX mRNA expression combined with IDH1/2 mutational status and Ki-67 expression refines the molecular classification of astrocytic tumors: evidence from the whole transcriptome sequencing of 169 samples samples. Oncotarget. 2014; 5:2551-2561.

28. Metellus P, Coulibaly B, Colin C, de Paula AM, Vasiljevic A, Taieb D, et al. Absence of IDH mutation identifies a novel radiologic and molecular subtype of WHO grade II gliomas with dismal prognosis. Acta neuropathologica. 2010; 120:719-729.

29. Christensen BC, Smith AA, Zheng S, Koestler DC, Houseman EA, Marsit CJ, et al. DNA methylation, isocitrate dehydrogenase mutation, and survival in glioma. Journal of the National Cancer Institute. 2011; 103:143-153.

30. Nobusawa S, Watanabe T, Kleihues P, Ohgaki H. IDH1 mutations as molecular signature and predictive factor of secondary glioblastomas. Clinical cancer research : an official journal of the American Association for Cancer Research. 2009; 15:6002-6007.

31. Thon N, Eigenbrod S, Kreth S, Lutz J, Tonn JC, Kretzschmar H, et al. IDH1 mutations in grade II astrocytomas are associated with unfavorable progression-free survival and prolonged postrecurrence survival. Cancer. 2012; 118:452-460.

32. Takano S, Tian W, Matsuda M, Yamamoto T, Ishikawa E, Kaneko MK, et al. Detection of IDH1 mutation in human gliomas: comparison of immunohistochemistry and sequencing. Brain tumor pathology. 2011; 28:115-123.

33. Gravendeel LA, Kouwenhoven MC, Gevaert O, de Rooi JJ, Stubbs AP, Duijm JE, et al. Intrinsic gene expression profiles of gliomas are a better predictor of survival than histology. Cancer research. 2009; 69:9065-9072.

34. Kim YH, Nobusawa S, Mittelbronn M, Paulus W, Brokinkel B, Keyvani K, et al. Molecular classification of low-grade diffuse gliomas. The American journal of pathology. 2010; 177:2708-2714.

35. Hartmann C, Hentschel B, Tatagiba M, Schramm J, Schnell O, Seidel C, et al. Molecular markers in low-grade gliomas: predictive or prognostic?. Clinical cancer research : an official journal of the American Association for Cancer Research. 2011; 17:4588-4599.

36. Mukasa A, Takayanagi S, Saito K, Shibahara J, Tabei Y, Furuya K, et al. Significance of IDH mutations varies with tumor histology, grade, and genetics in Japanese glioma patients. Cancer science. 2012; 103:587-592.

37. Li S, Yan C, Huang L, Qiu X, Wang Z, Jiang T. Molecular prognostic factors of anaplastic oligodendroglial tumors and its relationship: a single institutional review of 77 patients from China. Neuro-oncology. 2012; 14:109-116.

38. Elsir T, Qu M, Berntsson SG, Orrego A, Olofsson T, Lindstrom MS, et al. PROX1 is a predictor of survival for gliomas WHO grade II. British journal of cancer. 2011; 104:1747-1754.

39. Ohka F, Natsume A, Motomura K, Kishida Y, Kondo Y, Abe $\mathrm{T}$, et al. The global DNA methylation surrogate LINE-1 methylation is correlated with MGMT promoter methylation and is a better prognostic factor for glioma. PloS one. 2011; 6:e23332.

40. Yao Y, Chan AK, Qin ZY, Chen LC, Zhang X, Pang JC, et al. Mutation analysis of IDH1 in paired gliomas revealed IDH1 mutation was not associated with malignant progression but predicted longer survival. PloS one. 2013; 8:e67421.

41. Yang M, Yuan Y, Zhang H, Yan M, Wang S, Feng F, et al. Prognostic significance of CD147 in patients with glioblastoma. Journal of neuro-oncology. 2013; 115:19-26.

42. Takahashi Y, Nakamura H, Makino K, Hide T, Muta D, Kamada H, et al. Prognostic value of isocitrate dehydrogenase 1, O6-methylguanine-DNA methyltransferase promoter methylation, and 1p19q co-deletion in Japanese malignant glioma patients. World journal of surgical oncology. 2013; 11:284.

43. Shin JH, Lee YS, Hong YK, Kang CS. Correlation between the prognostic value and the expression of the stem cell marker CD133 and isocitrate dehydrogenase 1 in glioblastomas. Journal of neuro-oncology. 2013; 115:333-341.

44. van den Bent MJ, Dubbink HJ, Marie Y, Brandes AA, Taphoorn MJ, Wesseling P, et al. IDH1 and IDH2 mutations are prognostic but not predictive for outcome in anaplastic oligodendroglial tumors: a report of the European Organization for Research and Treatment of Cancer Brain Tumor Group. Clinical cancer research : an official journal of the American Association for Cancer Research. 2010; 16:1597-1604.

45. de Tayrac M, Aubry M, Saikali S, Etcheverry A, Surbled C, Guenot F, et al. A 4-gene signature associated with clinical outcome in high-grade gliomas. Clinical cancer research : 
an official journal of the American Association for Cancer Research. 2011; 17:317-327.

46. Taal W, Dubbink HJ, Zonnenberg CB, Zonnenberg BA, Postma TJ, Gijtenbeek JM, et al. First-line temozolomide chemotherapy in progressive low-grade astrocytomas after radiotherapy: molecular characteristics in relation to response. Neuro-oncology. 2011; 13:235-241.

47. Lotsch D, Ghanim B, Laaber M, Wurm G, Weis S, Lenz S, et al. Prognostic significance of telomerase-associated parameters in glioblastoma: effect of patient age. Neurooncology. 2013; 15:423-432.

48. Leu S, von Felten S, Frank S, Vassella E, Vajtai I, Taylor E, et al. IDH/MGMT-driven molecular classification of lowgrade glioma is a strong predictor for long-term survival. Neuro-oncology. 2013; 15:469-479.

49. Okita Y, Narita Y, Miyakita Y, Ohno M, Matsushita Y, Fukushima S, et al. IDH1/2 mutation is a prognostic marker for survival and predicts response to chemotherapy for grade II gliomas concomitantly treated with radiation therapy. International journal of oncology. 2012; 41:1325-1336.

50. Ahmadi R, Stockhammer F, Becker N, Hohlen K, Misch M, Christians A, et al. No prognostic value of IDH1 mutations in a series of $100 \mathrm{WHO}$ grade II astrocytomas. Journal of neuro-oncology. 2012; 109:15-22.

51. Dahlrot RH, Kristensen BW, Hjelmborg J, Herrstedt J, Hansen S. A population-based study of low-grade gliomas and mutated isocitrate dehydrogenase 1 (IDH1). Journal of neuro-oncology. 2013; 114:309-317.

52. Chou AP, Chowdhury R, Li S, Chen W, Kim AJ, Piccioni DE, et al. Identification of retinol binding protein 1 promoter hypermethylation in isocitrate dehydrogenase 1 and 2 mutant gliomas. Journal of the National Cancer Institute. 2012; 104:1458-1469.

53. Boots-Sprenger SH, Sijben A, Rijntjes J, Tops BB, Idema AJ, Rivera AL, et al. Significance of complete 1p/19q co-deletion, IDH1 mutation and MGMT promoter methylation in gliomas: use with caution. Modern pathology : an official journal of the United States and Canadian Academy of Pathology, Inc. 2013; 26:922-929.

54. Juratli TA, Kirsch M, Geiger K, Klink B, Leipnitz E, Pinzer T, et al. The prognostic value of IDH mutations and MGMT promoter status in secondary high-grade gliomas. Journal of neuro-oncology. 2012; 110:325-333.

55. Myung JK, Cho HJ, Park CK, Kim SK, Phi JH, Park SH. IDH1 mutation of gliomas with long-term survival analysis. Oncology reports. 2012; 28:1639-1644.

56. Combs SE, Rieken S, Wick W, Abdollahi A, von Deimling A, Debus J, et al. Prognostic significance of IDH-1 and MGMT in patients with glioblastoma: one step forward, and one step back?. Radiat Oncol. 2011; 6:115.

57. Qi ST, Yu L, Lu YT, Ou YH, Li ZY, Wu LX, et al. IDH mutations occur frequently in Chinese glioma patients and predict longer survival but not response to concomitant chemoradiotherapy in anaplastic gliomas. Oncology reports. 2011;26:1479-1485.

58. Schittenhelm J, Mittelbronn M, Meyermann R, Melms A, Tatagiba M, Capper D. Confirmation of R132H mutation of isocitrate dehydrogenase 1 as an independent prognostic factor in anaplastic astrocytoma. Acta neuropathologica. 2011; 122:651-652.

59. Gorovets D, Kannan K, Shen R, Kastenhuber ER, Islamdoust N, Campos C, et al. IDH mutation and neuroglial developmental features define clinically distinct subclasses of lower grade diffuse astrocytic glioma. Clinical cancer research : an official journal of the American Association for Cancer Research. 2012; 18:2490-2501.

60. Lewandowska MA, Furtak J, Szylberg T, Roszkowski K, Windorbska W, Rytlewska J, et al. An analysis of the prognostic value of IDH1 (isocitrate dehydrogenase 1) mutation in Polish glioma patients. Molecular diagnosis \& therapy. $2014 ; 18: 45-53$.

61. Kizilbash SH, Giannini C, Voss JS, Decker PA, Jenkins RB, Hardie J, et al. The impact of concurrent temozolomide with adjuvant radiation and IDH mutation status among patients with anaplastic astrocytoma. Journal of neuro-oncology. 2014; 120:85-93.

62. Collins VP, Ichimura K, Di Y, Pearson D, Chan R, Thompson LC, et al. Prognostic and predictive markers in recurrent high grade glioma; results from the BR12 randomised trial. Acta neuropathologica communications. 2014; 2:68.

63. Baldock AL, Yagle K, Born DE, Ahn S, Trister AD, Neal $\mathrm{M}$, et al. Invasion and proliferation kinetics in enhancing gliomas predict IDH1 mutation status. Neuro-oncology. 2014; 16:779-786.

64. Yan H, Parsons DW, Jin G, McLendon R, Rasheed BA, Yuan W, et al. IDH1 and IDH2 mutations in gliomas. The New England journal of medicine. 2009; 360:765-773.

65. Wang Y LS, Zhang Z, Chen X, You G, Yang P, et al. Surgical extent impacts the value of the established prognosticators in glioblastoma patients: a prospective translational study in Asia. Head \& Neck Oncology. 2012; 23:80.

66. Philippe M BC, Carole C, Andre MP, Anne B, Stephane F. Triple-negative low-grade glioma:A highly aggressive tumor with dismal prognosis. Journal of Clinical Oncology. 2011; ASCO Annual Meeting Abstracts Part 1.

67. Takano S, Kato Y, Yamamoto T, Kaneko MK, Ishikawa E, Tsujimoto Y, et al. Immunohistochemical detection of IDH1 mutation, p53, and internexin as prognostic factors of glial tumors. Journal of neuro-oncology. 2012; 108:361-373.

68. Dang L, White DW, Gross S, Bennett BD, Bittinger MA, Driggers EM, et al. Cancer-associated IDH1 mutations produce 2-hydroxyglutarate. Nature. 2010; 465:966.

69. Koivunen P, Lee S, Duncan CG, Lopez G, Lu G, Ramkissoon S, et al. Transformation by the (R)-enantiomer of 2-hydroxyglutarate linked to EGLN activation. Nature. 2012; 483:484-488. 
70. Xu W, Yang H, Liu Y, Yang Y, Wang P, Kim SH, et al. Oncometabolite 2-hydroxyglutarate is a competitive inhibitor of alpha-ketoglutarate-dependent dioxygenases. Cancer cell. 2011; 19:17-30.

71. Jin G, Reitman ZJ, Spasojevic I, Batinic-Haberle I, Yang J, Schmidt-Kittler O, et al. 2-hydroxyglutarate production, but not dominant negative function, is conferred by gliomaderived NADP-dependent isocitrate dehydrogenase mutations. PloS one. 2011; 6:e16812.

72. Turcan S, Rohle D, Goenka A, Walsh LA, Fang F, Yilmaz E, et al. IDH1 mutation is sufficient to establish the glioma hypermethylator phenotype. Nature. 2012; 483:479-483.

73. Sturm D, Witt H, Hovestadt V, Khuong-Quang DA, Jones DT, Konermann C, et al. Hotspot mutations in
H3F3A and IDH1 define distinct epigenetic and biological subgroups of glioblastoma. Cancer cell. 2012; 22:425-437.

74. Kato Y, Jin G, Kuan CT, McLendon RE, Yan H, Bigner DD. A monoclonal antibody IMab-1 specifically recognizes IDH1R132H, the most common glioma-derived mutation. Biochemical and biophysical research communications. 2009; 390:547-551.

75. Cheng HB, Yue W, Xie C, Zhang RY, Hu SS, Wang Z. IDH1 mutation is associated with improved overall survival in patients with glioblastoma: a meta-analysis. Tumour biology : the journal of the International Society for Oncodevelopmental Biology and Medicine. 2013; 34:3555-3559. 